\title{
Modulation of the Extracellular
} 5-Hydroxytryptamine Brain Concentrations by the Serotonin and Noradrenaline Reuptake Inhibitor, Milnacipran

\section{Microdialysis Studies in Rats}

Núria Bel, Ph.D. and Francesc Artigas, Ph.D.

We examined the effects of the administration of milnacipran, a dual inhibitor of serotonin (5-hydroxytryptamine, 5-HT) and noradrenaline uptake on the 5-HT output in rat brain. Local milnacipran administration increased the 5-HT output in frontal cortex and the midbrain raphe nuclei 7- and 10-fold by a $\mathrm{Ca}^{2+}$ - and tetrodotoxin-dependent mechanism. However, the subcutaneous administration of milnacipran (1-60 $\mathrm{mg} / \mathrm{kg}$ SC) elevated the 5-HT output much less in these areas (200-230\% of baseline at $60 \mathrm{mg} / \mathrm{kg}$ ). In hypothalamus, 10 $\mathrm{mg} / \mathrm{kg}$ SC raised 5 - HT levels to $170 \%$. The $5-H T_{1 A}$ antagonist WAY-100635 caused a small potentiation of the effects of milnacipran. The baseline 5-HT output was unaffected by 2-week treatments with milnacipran (30 and $60 \mathrm{mg} / \mathrm{kg} \cdot$ day). The distinct regional profile and the lack of enhancement of its effects by WAY-100635 and prolonged treatment suggest that milnacipran does not exert its antidepressant action through an enhancement of the serotonergic function. [Neuropsychopharmacology 21:745-754, 1999] (C) 1999 American College of Neuropsychopharmacology. Published by Elsevier Science Inc.
KEY WORDS: 5-HT uptake; 5-HT 1 receptors;

Antidepressants; Frontal cortex; Hypothalamus; Raphe; Selective serotonin reuptake inhibitors

The administration of selective 5-HT reuptake inhibitors (SSRIs), monoamine oxidase inhibitors (MAOIs), and clomipramine markedly increases the extracellular concentration of 5-HT in the raphe nuclei of the midbrain (Adell and Artigas 1991; Bel and Artigas 1992; Invernizzi et al. 1992; Celada and Artigas 1993; Gartside

From the Department of Neurochemistry, Instituto de Investigaciones Biomédicas de Barcelona (CSIC), IDIBAPS, Barcelona, Spain.

Address correspondence to: Dr. F. Artigas, Instituto de Investigaciones Biomédicas de Barcelona, IDIBAPS, Department of Neurochemistry, Rosselló 161, 08036 Barcelona, Spain.

Received January 17, 1999; revised May 21, 1999; accepted June 18,1999 . et al. 1995; Malagié et al. 1995). In all instances, these elevations are superior to those produced in frontal cortex or, when examined, in hippocampus. The excess 5 -HT in the extracellular space of the midbrain raphe activates $5-\mathrm{HT}_{1 \mathrm{~A}}$ autoreceptors in the soma and dendrites of serotonergic neurones and reduces the neuronal activity and release of 5-HT by nerve terminals in forebrain (see Artigas et al. 1996 for review).

Selective serotonin (5-hydroxytryptamine, 5-HT) and noradrenaline reuptake inhibitors (SNRIs) are a new class of antidepressant drugs. These agents inhibit in vitro the neuronal uptake of 5-HT and noradrenaline without exhibiting significant activity at the dopamine transporter or aminergic receptors (see Artigas 1995; Briley 1998 for review). Consequently, they are devoid of the unwanted side effects of classic antidepressant 
drugs, mainly derived from their affinity for $\alpha$-adrenergic, cholinergic, and histamine receptors (Richelson 1978; Richelson and Nelson 1984). Milnacipran is one such drug that blocks in vitro and in vivo the reuptake of 5-HT and noradrenaline, although it displays a slightly higher affinity for the latter (Moret et al. 1985; Stenger et al. 1987).

Despite the potential advantages of SNRIs, the information on their in vivo effects on serotonergic transmission is scarce (e.g., Engleman et al. 1995; 1996). In particular, a comparison of their effects in the somatodendritic region in the raphe nuclei and in forebrain has not been performed. Data obtained with the microdialysis technique suggest that the dual blockade of the 5-HT and noradrenaline transporters elevates the extracellular 5-HT concentration in rat brain, with a regional profile different from that of SSRIs (Bel and Artigas 1996). Because an increment of 5-HT in forebrain may be relevant for the clinical effects of antidepressant drugs (Blier and de Montigny 1994; Artigas et al. 1996), we have conducted the present microdialysis study aimed at examining the modifications of extracellular 5-HT induced by milnacipran in rat brain.

\section{MATERIAL AND METHODS}

\section{Animals}

Male Wistar rats (Iffa Credo, Lyon, France) weighing 280 to $320 \mathrm{~g}$ were used. Animals were kept in a controlled environment $\left(12 \mathrm{~h}\right.$ light-dark cycle and $22 \pm 2^{\circ} \mathrm{C}$ room temperature). Food and water were provided ad libitum before and during microdialysis experiments. Animal care followed the Spanish legislation on "Protection of Animals Used in Experimental and Other Scientific Purposes," in agreement with the European Union regulations (EEC Council Directive 86/609 of 24 November 1986).

\section{Drugs and Treatments}

5-HT, tetrodotoxin (TTX), and WAY-100635 [N-(2-(4-2methoxyphenyl)-1-piperazinyl)ethyl)-N-(2-pyridyl)cyclohexanecarboxamide $3 \mathrm{HCl}$ ] were obtained from RBI (Natick, MA). Milnacipran was obtained from Pierre Fabre Médicament (Castres, France). Other materials and reagents were from local commercial sources. All drug doses are expressed as the base. For local applications, appropriate amounts of milnacipran and TTX were dissolved in the artificial CSF used to perfuse the probes (final concentrations of milnacipran: 10, 100, and $1,000 \mu \mathrm{mol} / \mathrm{l}$; tetrodotoxin was perfused at $1 \mu \mathrm{mol} / \mathrm{l}$ ). In a separate group of animals, the perfusion fluid (see below) was changed to one devoid of $\mathrm{Ca}^{2+}$ ions for 1 hour while perfusing milnacipran. Probes were perfused again with the normal perfusion fluid containing
$1 \mathrm{mmol} / 1 \mathrm{milnacipran}$ ( 1 hour, restabilization period) and $1 \mathrm{mmol} / 1$ milnacipran plus $1 \mu \mathrm{mol} / 1$ TTX ( 1 additional hour). Acute systemic administrations of milnacipran were carried out SC or IP. For chronic administrations to rats, osmotic minipumps (Alzet 2002) were used. Two different doses were used, 30 and $60 \mathrm{mg} /$ $\mathrm{kg} \cdot$ day. Given the weight gain, these corresponded to the 7 th day of the treatment. The minipumps of control animals were filled with saline. Minipumps were implanted SC under light ether anesthesia. Animals were housed one per cage. On the 14th day of treatment (1 day after probe implant), rats received a challenge dose of $30 \mathrm{mg} / \mathrm{kg}$ SC milnacipran. After killing the rats, the minipumps were removed, cut with a surgical blade, and checked by visual inspection that they had delivered their content.

\section{Surgery and Microdialysis Procedures}

Microdialysis procedures in rats were carried out essentially as described in Adell and Artigas (1991). Concentric dialysis probes were used, equipped with $\mathrm{Cu}$ prophan membranes having a cut-off limit of 6,000 daltons (Gambro, Lund, Sweden). The length of membrane exposed to the brain tissue in rats was $3.5 \mathrm{~mm}$ for all regions sampled, frontal cortex, raphe nuclei, and hypothalamus (o.d. $0.25 \mathrm{~mm}$ ). Although the microdialysis technique enables separate sampling of the dorsal and median raphe nuclei (e.g., Casanovas and Artigas 1996), we performed this study with longer probes, because this permitted the comparison with previous data obtained with the same type of probes using such reference antidepressants as clomipramine (Adell and Artigas 1991) or imipramine (Bel and Artigas 1996). At the stereotaxic coordinates used (see below), these probes sampled the lateral parts of the dorsal and median raphe nuclei and a very high density of efferent serotonergic fibers (Halliday et al. 1995). Before implantation, rats were anesthesized with sodium pentobarbital $(60 \mathrm{mg} / \mathrm{kg} \mathrm{IP})$ and placed in a David Kopf stereotaxic frame. The stereotaxic coordinates (in $\mathrm{mm}$ ) for the raphe nuclei (AP - 7.8, DV - 9.0, L - 0.5), frontal cortex (AP + 3.2, DV - 6.0, L + 2.5) and hypothalamus $(\mathrm{AP}-2.8, \mathrm{DV}-9.5, \mathrm{~L}-0.5)$ were taken from bregma and surface of the skull according to the rat brain atlas of Paxinos and Watson (1986).

Animals were allowed to recover from surgery in metacrylate dialysis cages (cubic, $40-\mathrm{cm}$ side). On the day after surgery (20-24 $\mathrm{h}$ after), the probes were perfused with artificial cerebrospinal fluid (CSF) (125 $\mathrm{mmol} / 1 \mathrm{NaCl}, 2.5 \mathrm{mmol} / 1 \mathrm{KCl}, 1.26 \mathrm{mmol} / 1 \mathrm{CaCl}_{2}$ and $1.18 \mathrm{mmol} / 1 \mathrm{MgCl}_{2}$ ) at $0.5 \mathrm{ml} / \mathrm{min}$ using a microinjection pump (CMA or Harvard) and liquid swivels (Instech, Plymouth, MA). $\mathrm{Ca}^{2+}$-free perfusion fluid was made up by isosmotic replacement of $\mathrm{CaCl}_{2}$ with $\mathrm{MgCl}_{2}$. Sample collection started $60 \mathrm{~min}$ after the begin- 
ning of perfusion. After a 1-h equilibration period, 4 to 5 fractions were collected to obtain basal values before local or systemic administration of drugs. For local delivery of milnacipran and TTX, aliquots of concentrated solutions were dissolved in the artificial CSF used to perfuse the probes. When necessary, the $\mathrm{pH}$ of concentrated drug solutions was adjusted to $\sim 7$ with $\mathrm{NaHCO}_{3}$. After collection of baseline fractions, successive $30 \mathrm{~min}(15 \mu \mathrm{l})$ dialysate samples were collected. At the end of the experiments, the correct placement of the probes was checked by infusing methylene blue through the probe and inspecting the entire course under a stereo microscope after cutting the brains at the appropriate level. The data of animals with the probes outside the structures of interest were not included in the calculations.

\section{Chromatographic Analysis}

Rat brain dialysate samples were analyzed by a modification of a high-performance liquid chromatography (HPLC) method previously described (Adell and Artigas 1991). The composition of HPLC eluant was as follows: $150 \mathrm{mmol} / 1 \mathrm{Na}_{2} \mathrm{HPO}_{4}, 1.3 \mathrm{mmol} / 1$ octyl sodium sulphate, $0.2 \mathrm{mmol} / 1$ EDTA ( $\mathrm{pH} 2.8$ adjusted with phosphoric acid) plus $27 \%$ methanol. 5 -HT was separated on a $3 \mu \mathrm{m}$ ODS two-column $(7.5 \mathrm{~cm} \times 0.46 \mathrm{~cm}$; Beckman, San Ramón, CA) and detected amperometrically with a Hewlett-Packard 1049 detector (oxidation potential +0.6 V). Retention time for 5-HT was 3.5 to $4 \mathrm{~min}$.

\section{Data Treatment}

Microdialysis results are given as raw data (fmol per 30 -min fractions) and represented in most figures as percentages of baseline values, calculated as the indi-

\section{Raphe nuclei}

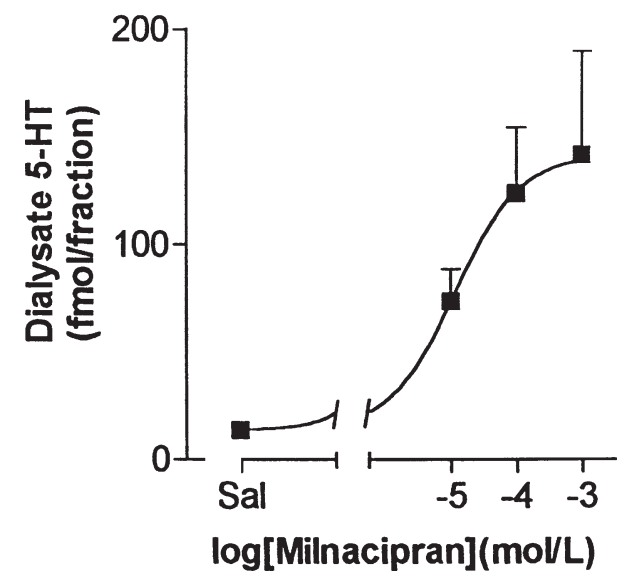

vidual means of four fractions before drug administration. The effects of the local administration of milnacipran are given as the individual means of two dialysate fractions $(1 \mathrm{~h})$ for each concentration. Statistical analysis was performed with the raw (nontransformed) data using one- or two-way analysis of variance (ANOVA) for independent or repeated measures and post-ANOVA tests for multiple comparisons, where appropriate. The $\mathrm{EC}_{50}$ values of the local effects of milnacipran in rat brain were calculated by using the GraphPad Prism software (San Diego, CA). Data are expressed as means \pm SEM. Statistical significance has been set at the $95 \%$ confidence level (two-tailed).

\section{RESULTS}

\section{Baseline Dialysate Values}

Untreated rats had a baseline 5-HT concentration of $4.0 \pm$ $0.3(n=57), 10.8 \pm 0.9(n=53)$ and $5.6 \pm 0.7(n=13)$ $\mathrm{fmol} /$ fraction in dialysates from frontal cortex, the midbrain raphe nuclei, and hypothalamus, respectively.

\section{Local Effects of Milnacipran}

The infusion of milnacipran $(10 \mu \mathrm{mol} / \mathrm{l}-1 \mathrm{mmol} / \mathrm{l})$ by reverse dialysis raised significantly the 5-HT output in frontal cortex and raphe nuclei $(p<.001$ and .003 , respectively; repeated measures ANOVA). The calculated $\mathrm{EC}_{50}$ values for the 5-HT-induced elevation in frontal cortex and raphe nuclei were, respectively, 11.4 and $11.6 \mu \mathrm{mol} / 1$, respectively (Figure 1 ). In another group of rats, the local infusion of $1 \mathrm{mmol} / 1$ milnacipran elevated about 11 -fold the dialysate 5 -HT concentration in frontal cortex. The omission of $\mathrm{Ca}^{2+}$ ions from the perfusion fluid and the addition of $1 \mu \mathrm{mol} / 1$ TTX mark-

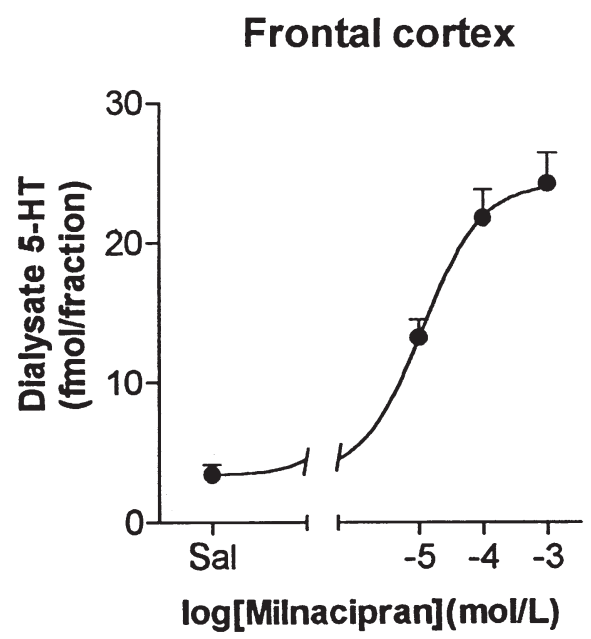

Figure 1. Concentration-dependent increment of the 5-HT concentration in dialysates from raphe nuclei $(n=7)$ and frontal cortex $(n=7)$ induced by the local infusion of milnacipran $(10 \mu \mathrm{mol} / 1-1 \mathrm{mmol} / \mathrm{l})$ by reverse dialysis in rat brain. The calculated $\mathrm{EC}_{50}$ values were 11.4 and $11.6 \mu \mathrm{mol} / 1$ for frontal cortex and raphe nuclei, respectively. 


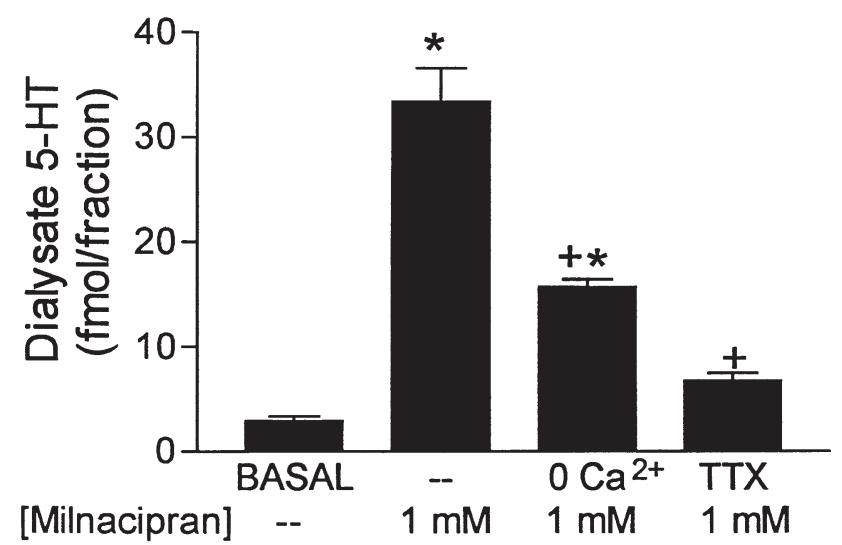

Figure 2. Effects of the omission of $\mathrm{Ca}^{2+}$ ions and the addition of $1 \mu \mathrm{mol} / 1 \mathrm{TTX}$ on the elevation of 5-HT in dialysates from rat frontal cortex elicited by the local infusion of milnacipran $(1 \mathrm{mmol} / \mathrm{l})(n=5)$. Bars are the mean \pm SEM values of 1-hour dialysate 5-HT values (except basals, 2 h) during the infusion of $1 \mathrm{mmol} / 1$ milnacipran using a normal perfusion fluid, one without $\mathrm{Ca}^{2+}$ ions $\left(0 \mathrm{Ca}^{2+}\right)$ or one with normal $\mathrm{Ca}^{2+}$ concentration supplemented with $1 \mu \mathrm{mol} / 1$ tetrodotoxin (TTX). $p<.0001$, repeated measures ANOVA; $\left(^{*}\right)$ significantly different from baseline; $(+)$ significantly different from milnacipran; post hoc $t$-test.

edly attenuated the effect of milnacipran (47 and $20 \%$ of post-milnacipran values, respectively; $p<.0001$, repeated measures ANOVA) (Figure 2).

\section{Effects of the Systemic Administration of Single Milnacipran Doses on the 5-HT Output}

Milnacipran elevated dose-dependently the concentration of 5-HT in dialysates from frontal cortex and raphe nuclei $(p<.001$, time effect; $p<.001$, time $\times$ dose interaction in both areas; two-way repeated measures ANOVA) (Figure 3).

The administration of $60 \mathrm{mg} / \mathrm{kg}$ SC milnacipran elicited a clear and long-lasting elevation in frontal cortex and the raphe nuclei $(p<.001$ in both areas; one-way repeated measures ANOVA). Averaged post-treatment values are shown in Table 1. One-way ANOVA of the data indicated the existence of a significant effect of the treatment $(p<.001)$ and a significant difference between the dose of $60 \mathrm{mg} / \mathrm{kg}$ and the rest of treatments in the two regions examined (Tukey test). No significant differences were noted between lower doses $(1,10$, and $30 \mathrm{mg} / \mathrm{kg}$ ) and controls, although there was a tendency toward elevated 5-HT values in animals treated with 10 and $30 \mathrm{mg} / \mathrm{kg}$ SC milnacipran.

In hypothalamus, the SC injection of $10 \mathrm{mg} / \mathrm{kg}$ milnacipran elicited a clear-cut increment of dialysate 5HT (maximal increase to $172 \%$ of baseline), which was significantly different from the effect of a saline injection $(p<.001$, time effect; $p<.001$ time $\times$ dose interaction; ANOVA for repeated measures) (Figure 4). This elevation was more marked and long-lasting than that induced in frontal cortex and the raphe nuclei by the same milnacipran dose $(p<.001$, effect of region; $p<$ .001 effect of time; $p<.028$, time $\times$ region interaction).

\section{Combination Experiments: Effects of the Administration of Milnacipran and WAY-100635}

Figure 5 shows the effects of the combined administration of milnacipran $60 \mathrm{mg} / \mathrm{kg}$ and WAY-100635 (1 mg/ $\mathrm{kg} \mathrm{SC}$ ) on the 5-HT concentration in dialysates from the raphe nuclei and frontal cortex. In the former region,

\section{FRONTAL CORTEX}

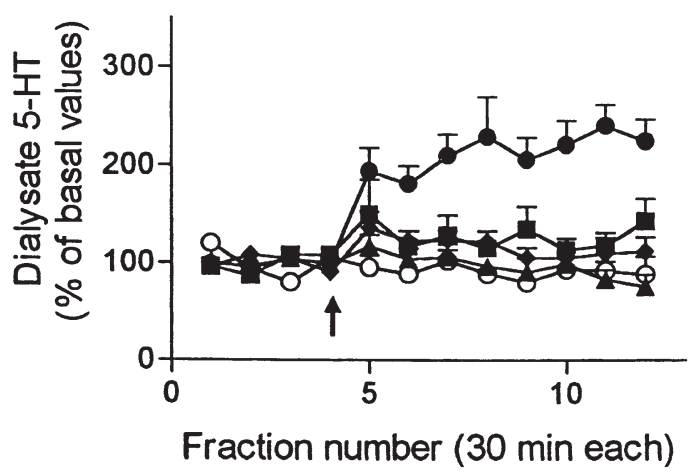

RAPHE NUCLEI

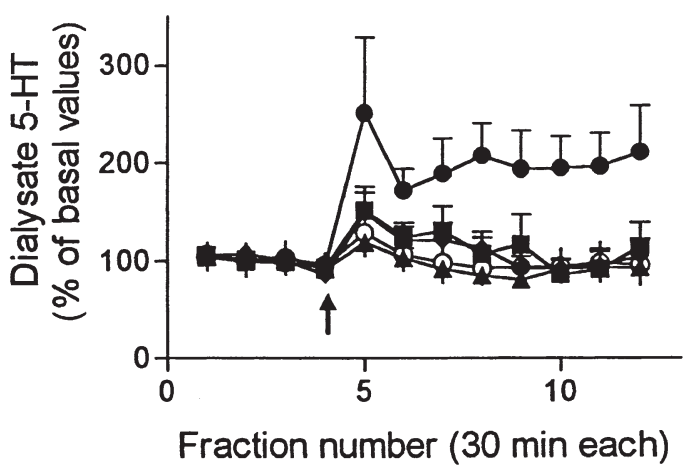

Figure 3. Left panel. Effects of the administration of single doses of milnacipran (1, 10,30, and $60 \mathrm{mg} / \mathrm{kg} \mathrm{SC}$, marked by an arrow) on dialysate 5-HT concentrations in rat frontal cortex. The number of animals in each group is as follows: saline, (open circles) $n=4 ; 1 \mathrm{mg} / \mathrm{kg}$ (triangles), $n=7 ; 10 \mathrm{mg} / \mathrm{kg}$ (diamonds), $n=7 ; 30 \mathrm{mg} / \mathrm{kg}$ (squares), $n=6 ; 60 \mathrm{mg} / \mathrm{kg}$ (circles), $n=8$. Right panel. Effects of the administration of single doses of milnacipran $(1,10,30$, and $60 \mathrm{mg} / \mathrm{kg}) \mathrm{on}$ dialysate 5 - $\mathrm{HT}$ concentrations in raphe nuclei. Number of animals in each group is as follows: saline (open circles), $n=5 ; 1 \mathrm{mg} / \mathrm{kg}$ (triangles), $n=7 ; 10 \mathrm{mg} / \mathrm{kg}$ (diamonds), $n=6 ; 30 \mathrm{mg} / \mathrm{kg}$ (squares), $n=6 ; 60 \mathrm{mg} / \mathrm{kg}$ (circles) $n=8$. See text for statistical analysis. 
Table 1. Effect of Milnacipran Administration on Dialysate 5-HT Concentration in Rat Brain

\begin{tabular}{lcc}
\hline & Frontal Cortex & Raphe Nuclei \\
\hline Saline sc & $76 \pm 2(4)$ & $96 \pm 2(5)$ \\
$1 \mathrm{mg} / \mathrm{kg} \mathrm{sc}$ & $96 \pm 10(7)$ & $95 \pm 4(7)$ \\
$10 \mathrm{mg} / \mathrm{kg} \mathrm{sc}$ & $117 \pm 9(7)$ & $112 \pm 13(6)$ \\
$30 \mathrm{mg} / \mathrm{kg} \mathrm{sc}$ & $127 \pm 13(6)$ & $115 \pm 21(6)$ \\
$60 \mathrm{mg} / \mathrm{kg} \mathrm{sc}$ & $213 \pm 20^{*}(8)$ & $202 \pm 38^{*}(8)$ \\
\hline
\end{tabular}

Data are averaged post-treatment 5-HT concentrations in dialysates from frontal cortex and raphe nuclei, expressed as individual percentages of baseline values. ( ${ }^{*} p<.05$ vs. controls; Tukey tests). Number of animals shown in brackets.

milnacipran elevated dialysate $5-\mathrm{HT}$ to about $250 \%$ of baseline in both groups $(p<.001$, time effect; ns time $\times$ treatment interaction). The administration of WAY100635 (but not that of saline) to milnacipran-treated rats further enhanced the 5-HT concentration to $365 \%$ of baseline $(p<.001$, time effect; $p<.001$ treatment $\times$ time interaction). In frontal cortex, milnacipran elevated significantly dialysate 5-HT $(p<.001)$. The subsequent administration of WAY-100635 did not result in a significant potentiation of the 5-HT increase induced by milnacipran, as compared to the effect of a saline injection $(p=.10$, time $\times$ treatment interaction).

\section{Effects of the Continuous Administration of Milnacipran with Minipumps}

Table 2 shows the effects of the continuous administration of milnacipran for 2 weeks ( 30 and $60 \mathrm{mg} / \mathrm{kg} \cdot$ day) on the basal 5-HT concentrations in the raphe nuclei and frontal cortex. One-way ANOVA revealed a signif-

\section{HYPOTHALAMUS}

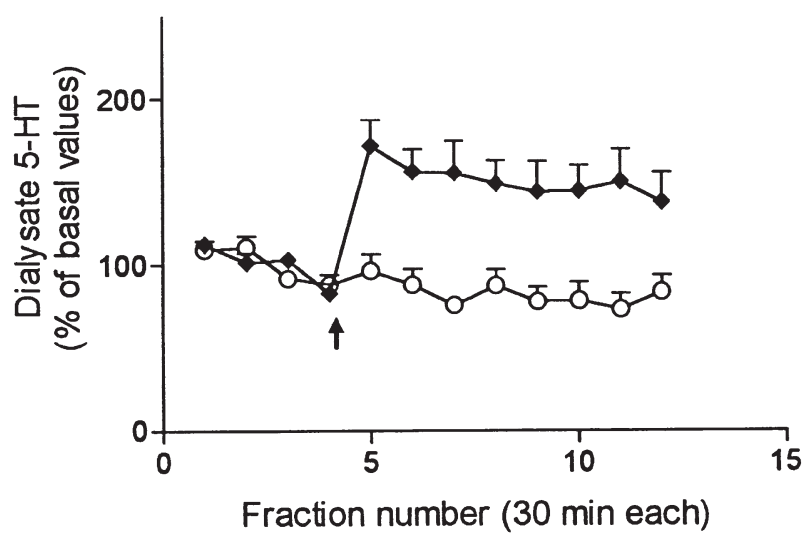

Figure 4. The administration of $10 \mathrm{mg} / \mathrm{kg}$ SC milnacipran elevated the dialysate 5-HT concentration in rat hypothalamus (diamonds, $n=7$ ). Control animals received saline (open circles, $n=6$ ). Injections are marked by an arrow. See text for statistical details. icant effect of the treatment on baseline 5-HT concentration in frontal cortex $(p<.025)$ and a significantly lower value in the rats treated with 30 (but not 60 ) $\mathrm{mg} / \mathrm{kg}$-day milnacipran $(p<.05$, Tukey test). No significant differences were noted in the raphe nuclei.

The pretreatment with milnacipran prevented the elevation induced by a challenge injection of $30 \mathrm{mg} / \mathrm{kg}$ $\mathrm{SC}$ in frontal cortex of control (saline-treated) rats $(p<$ .001 , time effect; $p<.006$ treatment $\times$ time interaction; Figure 6). In the raphe nuclei, there was a tendency toward an opposite situation, as the effects of the challenge milnacipran dose seemed to be slightly more marked in milnacipran-treated rats, but this difference did not reach statistical significance $(p=.299$, treatment $X$ time interaction).

\section{DISCUSSION}

The present results indicate that milnacipran elevates the extracellular 5-HT concentration in rat brain, as assessed by in vivo microdialysis. The 5-HT elevations in frontal cortex and raphe nuclei were comparable. This regional selectivity is different from that of agents that selectively block 5-HT reuptake, which enhances extracellular 5-HT more in the raphe nuclei than in frontal cortex (Adell and Artigas 1991; Bel and Artigas 1992; Invernizzi et al. 1992; Malagié et al. 1995; Hervás and Artigas 1998).

Milnacipran markedly elevated the 5-HT output in rat brain when administered by reverse dialysis (7- and 10 -fold in frontal cortex and midbrain, respectively). The antagonism of this effect by the omission of $\mathrm{Ca}^{2+}$ ions and the addition of TTX indicates that milnacipran elevated the 5-HT output by blockade of the reuptake of the 5-HT released by an impulse-dependent mechanism and not by a fenfluramine-like releasing action, because the latter is insensitive to the blockade of nerve transmission (Carboni and Di Chiara 1989). The inhibition of the 5-HT output produced by TTX in presence of milnacipran was similar to that observed previously for basal 5-HT (Carboni and Di Chiara 1989; Auerbach et al. 1989; Sharp et al. 1990). The relatively smaller effect of the omission of $\mathrm{Ca}^{2+}$ ions is also consistent with previous observations on basal 5-HT release (Auerbach et al. 1989; Sharp et al. 1990) and is likely attributable to the fact that endogenous $\mathrm{Ca}^{2+}$ stores in the tissue are sufficient to maintain a substantial degree of neuronal 5-HT release.

The $\mathrm{EC}_{50}$ values obtained for milnacipran $(\sim 11$ $\mu \mathrm{mol} / \mathrm{l})$ are comparable to those found for clomipramine (Adell and Artigas 1991) and imipramine (Bel and Artigas 1996) using the same methodology and probe type and size. However, the calculated $\mathrm{EC}_{50}$ values were close to the lower milnacipran concentration used, which may reduce the accuracy of this measure. 


\section{RAPHE NUCLEI}

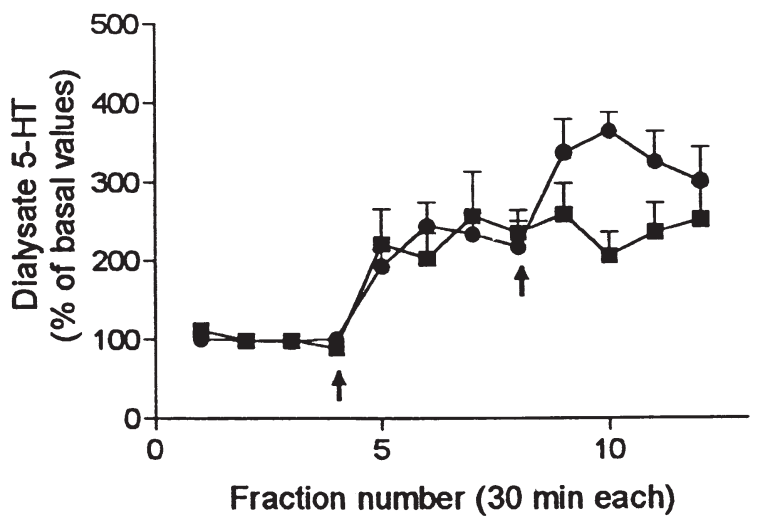

FRONTAL CORTEX

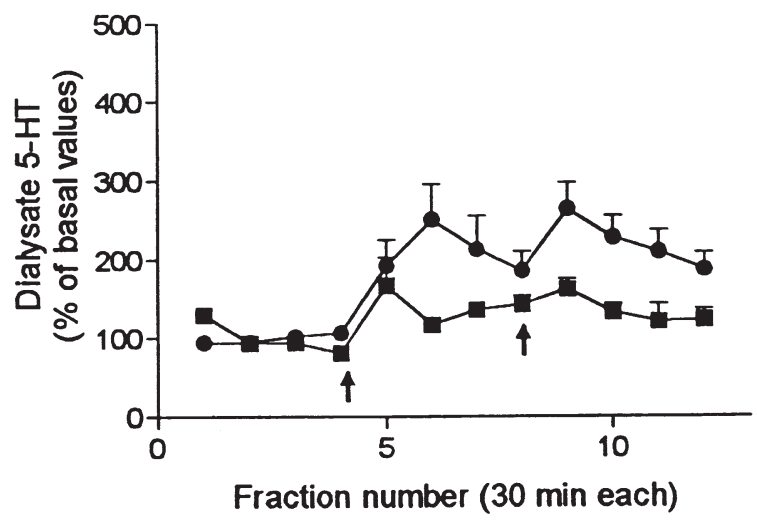

Figure 5. Left panel. Potentiation of the milnacipran-induced elevation of 5-HT in the raphe nuclei of rats by the administration of WAY-100635 (1 mg/kg s.c.). Milnacipran $60 \mathrm{mg} / \mathrm{kg}$ SC plus saline: filled squares $(n=6) ;$ milnacipran $60 \mathrm{mg} / \mathrm{kg}$ SC plus WAY-100635 $1 \mathrm{mg} / \mathrm{kg}$ SC: filled circles $(n=8)$. Right panel. WAY-100635 caused a very moderate and transient elevation of dialysate 5-HT in frontal cortex that was not significantly different from that of a saline injection in milnacipranpretreated rats. Milnacipran $60 \mathrm{mg} / \mathrm{kg}$ SC plus saline: filled squares $(n=5)$; milnacipran $60 \mathrm{mg} / \mathrm{kg}$ SC plus WAY-100635 1 $\mathrm{mg} / \mathrm{kg} \mathrm{SC}$ : filled circles $(n=8)$. First and second arrows mark the injection of milnacipran and saline or WAY-100635, respectively.

The experimental conditions used in vivo (low flow rate, continuous removal of applied drugs by the CSF and systemic circulation, tortuosity of brain tissue, etc.) make these values much higher than their corresponding in vitro counterparts (the in vitro value for the 5-HT uptake is $203 \mathrm{nM}$; Moret et al. 1985).

The maximal increments affected by milnacipran were very large (7- and 10-fold in frontal cortex and midbrain raphe, respectively) and comparable to those induced by the local application of SSRIs (Romero et al. 1997; Hervás and Artigas 1998.) This suggests that milnacipran blocks the 5-HT reuptake in vivo in rat brain with a potency in the range of that of imipramine or clomipramine. This is in agreement with the similar in vivo potency of imipramine and milnacipran to prevent the hypothermic and hyperthermic action of H75/12 and H77/77, respectively, which are related to the availability of brain monoamines (Moret et al. 1985).

Table 2. Effects of the 2-Week Administration of Milnancipran on Baseline Dialysate 5-HT Concentration in Rat Brain

\begin{tabular}{lcc}
\hline & Frontal Cortex & Raphe Nuclei \\
\hline $\begin{array}{l}\text { Saline } \\
\text { Milnacipran } 30\end{array}$ & $7.2 \pm 0.7(9)$ & $10.7 \pm 1.3(0)$ \\
$\mathrm{mg} / \mathrm{kg} \cdot$ day \\
$\begin{array}{r}\text { Milnacipran } 60 \\
\mathrm{mg} / \mathrm{kg} \cdot \text { day }\end{array}$ & $4.4 \pm 0.9(7)^{*}$ & $9.9 \pm 1.5(8)$ \\
\hline
\end{tabular}

${ }^{*} p<.025$, Tukey test vs. saline-treated animals. Data are expressed in fmol/30-min fraction. Number of animals shown in brackets.
However, 10 to $20 \mathrm{mg} / \mathrm{kg}$ clomipramine and imipramine increased 3- to 4-fold the 5-HT output in the midbrain raphe nuclei; whereas, $60 \mathrm{mg} / \mathrm{kg}$ milnacipran scarcely doubled the 5-HT output (Figure 3). Moreover, $10 \mathrm{mg} / \mathrm{kg}$ of the SSRI fluoxetine (with an $\mathrm{EC}_{50}$ of about $30 \mu \mathrm{mol} / \mathrm{l}$ ) increased the 5-HT output 3-fold in the dorsal and the median raphe nucleus (Hervás and Artigas 1998). The transient rise in 5-HT observed in the raphe nuclei after $60 \mathrm{mg} / \mathrm{kg}$ milnacipran may be related to the effects of the injection stress in the raphe nuclei (Adell et al. 1997), because a previous study showed maximal increments of the 5-HT and NA output 60 to $100 \mathrm{~min}$ after its administration (Moret and Briley 1997).

One possible explanation for the lesser effect of milnacipran as compared to imipramine or clomipramine could be a limited penetration of milnacipran in rat brain. This might account for the greater effect of the 10 $\mathrm{mg} / \mathrm{kg}$ dose in hypothalamus, partly outside the blood-brain barrier. In guinea pig hypothalamus, 10 $\mathrm{mg} / \mathrm{kg}$ milnacipran also doubled the basal dialysate 5-HT concentration (Moret and Briley 1997). Moreover, the SNRI duloxetine increased the 5-HT output in hypothalamus more markedly than in frontal cortex (Engleman et al. 1996; Kihara and Ikeda 1995). These observations suggest that hypothalamic 5-HT is particularly sensitive to the actions of SNRIs.

In addition, because milnacipran inhibits the noradrenaline uptake with a potency slightly greater than that of serotonin uptake ( $\mathrm{IC}_{50}$ values of 100 and $203 \mathrm{nM}$, respectively; Moret et al. 1985) an interaction between the noradrenergic and serotonergic systems cannot be disregarded as a potential source of these differences. Thus, the activation of $\alpha_{2}$-heteroceptors reduces termi- 
RAPHE NUCLEI

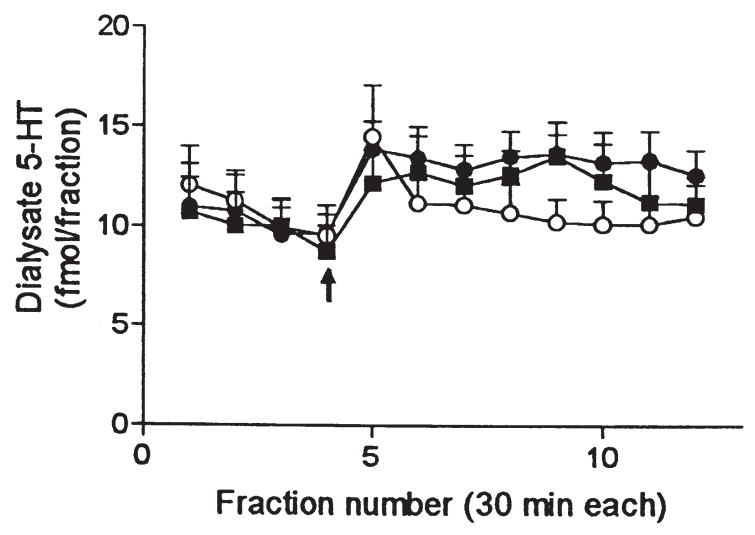

FRONTAL CORTEX

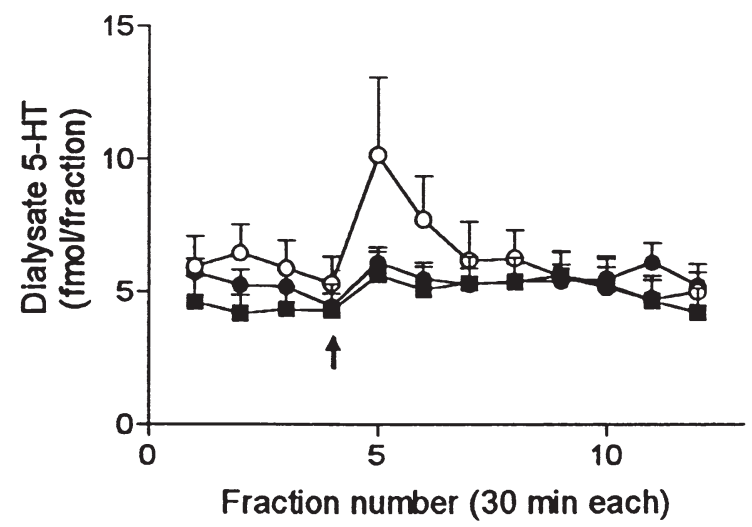

Figure 6. The continuous treatment in rats with minipumps with 30 or $60 \mathrm{mg} / \mathrm{kg}$-day milnacipran did not alter the baseline 5-HT concentrations in raphe nuclei (left panel). In frontal cortex (right panel), there was a moderate but significant reduction of the baseline 5-HT concentration in rats treated with milnacipran $30 \mathrm{mg} / \mathrm{kg} \cdot$ day as compared to controls (see Table 1). The effect of a challenge milnacipran dose $(30 \mathrm{mg} / \mathrm{kg} \mathrm{SC}$, marked by an arrow) was significantly lower in milnacipran-pretreated rats (see text for statistical analysis). No such difference was observed in the raphe nuclei. Data from 7 to 10 rats/group. Symbols are as follows: controls, open circles; milnacipran $30 \mathrm{mg} / \mathrm{kg} \cdot$ day, filled squares; milnacipran $60 \mathrm{mg} /$ $\mathrm{kg} \cdot$ day, filled squares.

nal 5-HT release (Starke and Montel 1973; Tao and Hjorth 1992; Bel and Artigas 1996), and the firing activity of serotonergic neurones is suppressed by clonidine and prazosin, $\alpha_{2}$-adrenoceptor agonist and $\alpha_{1}$-adrenoceptor antagonist, respectively (Svensson et al. 1975; Baraban and Aghajanian 1980). The short-term administration of milnacipran $(20 \mathrm{mg} / \mathrm{kg} \cdot$ day, 2 days $)$ reduces the firing rate of serotonergic neurones (Mongeau et al. 1998), an effect that, unlike the SSRIs, depends on the integrity of the noradrenergic system and the activation of $\alpha_{2}$-adrenoceptors (Mongeau et al. 1998). Thus, an enhancement of the function of $\alpha_{2}$ adrenoceptors or a reduction of the $\alpha_{1}$-mediated tone on serotonergic neurones (secondary to the inhibition of the firing of NA neurones (Mongeau et al. 1998) might also be involved in the comparatively lower increases of the 5-HT output produced by the systemic milnacipran administration. In support of this possibility, duloxetine increased the NA output more than that of 5-HT in hypothalamus and frontal cortex (Engleman et al. 1995; Kihara and Ikeda 1995), despite the fact that it preferentially blocks the 5-HT reuptake (relative 5-HT / NA ratio of 2.7; Artigas 1995). These observations are difficult to reconcile with the desipramine-induced potentiation of the increase in frontocortical 5-HT output produced by the SSRI fluoxetine (Bel and Artigas 1996). This was first attributed to the dual blockade of the 5-HT and NA reuptake, but in view of the present data, this hypothesis needs to be re-evaluated using more selective NA reuptake inhibitors.

The release of 5-HT in the raphe nuclei and in brain regions innervated by the dorsal raphe nucleus is offset by the activation of $5-\mathrm{HT}_{1 \mathrm{~A}}$ autoreceptors during the administration of 5-HT uptake inhibitors (see Artigas et al. 1996 for review). The selective $5-\mathrm{HT}_{1 \mathrm{~A}}$ antagonist WAY-100635 potentiated the 5-HT increment induced by milnacipran in the midbrain raphe nuclei, in agreement with previous data (Romero and Artigas 1997). However, this effect was very moderate, and the administration of WAY-100635 failed to augment the effect of milnacipran in frontal cortex. WAY-100635 markedly enhanced the 5-HT elevations induced by SSRIs and clomipramine in this brain region (Gartside et al. 1995; Malagié et al. 1996; Romero et al. 1996; Invernizzi et al. 1997; Romero and Artigas 1997). This effect results from the antagonism of the indirect actions of the SSRIs at raphe 5- $\mathrm{HT}_{1 \mathrm{~A}}$ autoreceptors, as shown by the local application of WAY-100635 in the dorsal raphe nucleus (Romero and Artigas 1997). Therefore, the lack of potentiation of the effect of milnacipran by WAY100635 in frontal cortex lies conceivably on a low tone of $5-\mathrm{HT}_{1 \mathrm{~A}}$ autoreceptors after its administration to rats, consistent with the small increments of the 5-HT output observed in the midbrain raphe. It is unclear whether this assumption can be extrapolated to other species, because the nonselective $5-\mathrm{HT}_{1 \mathrm{~A}} / \beta$-adrenoceptor antagonist (-)pindolol potentiated the 5-HT elevation elicited by milnacipran in guinea pig hypothalamus (Moret and Briley 1997). (-)Pindolol also enhanced the milnacipran-induced elevation in noradrenaline output (Moret and Briley 1997), a finding that agrees with the observations indicating that the effects on both amines of the SNRI duloxetine in rat brain can be potentiated by $5-\mathrm{HT}_{1 \mathrm{~A}}$ (Engleman et al. 1996) and $\alpha_{2}$-adreno- 
ceptor blockade (Gobert et al. 1997). These observations further support the existence of a complex interplay of the 5-HT and NA systems during the simultaneous blockade of the reuptake of both amines. Because duloxetine is more selective than milnacipran for the 5-HT reuptake, a higher activation of somatodendritic $5-\mathrm{HT}_{1 \mathrm{~A}}$ receptors can be expected after duloxetine administration, which would facilitate the effects of the concurrent administration of a $5-\mathrm{HT}_{1 \mathrm{~A}}$ receptor antagonist on the 5-HT output.

Two-week treatments with SSRIs increase the basal 5-HT output in frontal cortex or facilitate the effect of a challenge dose of the antidepressant (Bel and Artigas 1993; Invernizzi et al. 1994; Rutter et al. 1994; Moret and Briley 1996). This effect is thought to derive from the desensitization of $5-\mathrm{HT}_{1 \mathrm{~A}}$ autoreceptors after chronic blockade of the 5-HT reuptake (Blier and de Montigny 1994; Invernizzi et al. 1994). The unchanged basal 5-HT output in frontal cortex and raphe nuclei after a 2-week administration of milnacipran (30 and $60 \mathrm{mg} / \mathrm{kg} \cdot$ day) suggests that its antidepressant properties do not derive from an enhancement of the function of serotonergic neurones. This is also consistent with a low activation of $5-\mathrm{HT}_{1 \mathrm{~A}}$ autoreceptors, as observed in potentiation experiments.

The moderate reduction of the 5-HT output in rats treated with $30 \mathrm{mg} / \mathrm{kg}$.day milnacipran seems unrelated to the action of the drug, because basal levels were not different from controls at a higher dose $(60 \mathrm{mg} /$ $\mathrm{kg}$-day). The challenge injection of milnacipran elicited a marked increment of the 5-HT output in frontal cortex of control rats. This was more marked than in naive rats (Figures 3, 6) possibly because of the different housing conditions (rats treated chronically were housed one per cage) and a higher baseline stress in the latter. Indeed, physical and psychological stress elevate the 5-HT output in various brain regions (Pei et al. 1990; Shimizu et al. 1992; Kawahara et al. 1993; Yoshioka et al. 1995; Adell et al. 1997; Singewald et al. 1997). The absence of such a response in milnacipran-treated rats suggests that chronic treatment with this agent may prevent the rise in 5-HT produced by injection stress. Interestingly, unlike milnacipran, a 2-week treatment with duloxetine, which increases the 5-HT output more than milnacipran after a single treatment (Engleman et al. 1995; Kihara and Ikeda 1995), facilitated the effects of a challenge dose (Kihara and Ikeda 1995). Again, this difference may lie in the greater potency of duloxetine to inhibit the 5-HT reuptake.

In summary, the present results indicate that milnacipran markedly increases the 5-HT output after its local administration and that this effect derives from inhibition of the 5-HT reuptake. However, the effects of milnacipran on extracellular 5-HT in rat brain differ from those of the SSRIs in three respects; namely, regional selectivity, smaller potentiation by WAY 100635, and absence of an enhancement of the 5-HT output after chronic administration. This suggests that its clinical action is not mediated by an enhancement of the serotonergic function and likely involves other neurotransmitter(s). The smaller increments produced by its systemic administration suggest either a limited penetration of the blood-brain barrier, a NA-mediated attenuation of 5-HT release, or a combination of both. However, given some regional and species differences (e.g., Moret and Briley 1997) and the complex interplay between the NA and 5-HT systems, further work is required to clarify the mechanism of action of this and other SNRIs.

\section{ACKNOWLEDGMENTS}

This work was supported by Pierre Fabre and the Fondo de Investigación Sanitaria (Grant \#98/0697). Thanks are due to Leticia Campa for her skillful technical assistance.

\section{REFERENCES}

Adell A, Artigas F (1991): Differential effects of clomipramine given locally or systemically on extracellular 5hydroxytryptamine in raphe nuclei and frontal cortex. An in vivo microdialysis study. Naunyn-Schmied Arch Pharmacol 343:237-244

Adell A, Casanovas JM, Artigas F (1997): Comparative study in the rat of the actions of different types of stress on the release of 5-HT in raphe nuclei and forebrain areas. Neuropharmacology 36:745-751

Artigas F (1995): Selective serotonin/noradrenaline reuptake inhibitors (SNRIs): Pharmacology and therapeutic potential in the treatment of depressive disorders. CNS Drugs 4:79-89

Artigas F, Romero L, de Montigny C, Blier P (1996): Acceleration of the effect of selected antidepressant drugs in major depression by $5-\mathrm{HT}_{1 \mathrm{~A}}$ antagonists. Trends Neurosci 19:378-383

Auerbach SB, Minzenberg MJ, Wilkinson LO (1989): Extracellular serotonin and 5-hydroxyindoleacetic acid in hypothalamus of the unanesthetized rat measured by in vivo dialysis coupled to high-performance liquid chromatography with electrochemical detection: Dialysate serotonin reflects neuronal release. Brain Res 499:281290

Baraban JM, Aghajanian GK (1980): Suppression of firing activity of 5-HT neurons in the dorsal raphe by $\alpha$ adrenoceptor antagonists. Neuropharmacology 19:355363

Bel N, Artigas F (1992): Fluvoxamine preferentially increases extracellular 5-hydroxytryptamine in the raphe nuclei: An in vivo microdialysis study. Eur J Pharmacol 229:101-103

Bel N, Artigas F (1993): Chronic treatment with fluvoxamine increases extracellular serotonin in frontal cortex but not in raphe nuclei. Synapse 15:243-245

Bel N, Artigas F (1996): In vivo effects of the simultaneous 
blockade of serotonin and norepinephrine transporters on serotonergic function. Microdialysis studies. J Pharmacol Exp Ther 278:1064-1072

Blier P, de Montigny C (1994): Current advances and trends in the treatment of depression. Trends Pharmacol Sci 15:220-226

Briley M (1998): Specific serotonin and noradrenaline reuptake inhibitors (SNRIs). A review of their pharmacology, clinical efficacy, and tolerability. Human Psychopharmacol 13:99-111

Carboni E, Di Chiara G (1989): Serotonin release estimated by transcortical dialysis in freely moving animals. Neuroscience 32:637-645

Casanovas JM, Artigas F (1996): Differential effects of ipsapirone on 5-HT release in the dorsal and median raphe neuronal pathways. J Neurochem 67:1945-1952

Celada P, Artigas F (1993): Monoamine oxidase inhibitors increase preferentially extracellular 5-hydroxytryptamine in the midbrain raphe nuclei. A brain microdialysis study in the awake rat. Naunyn-Schmied Arch Pharmacol 347:583-590

Engleman EA, Perry KW, Mayle DA, Wong DT (1995): Simultaneous increases of extracellular monoamines in microdialysates from hypothalamus of conscious rats by duloxetine, a dual serotonin and norepinephrine uptake inhibitor. Neuropsychopharmacology 12:287-295

Engleman EA, Robertson DW, Thompson DC, Perry KW, Wong DT (1996): Antagonism of serotonin 5- $\mathrm{HT}_{1 \mathrm{~A}}$ receptors potentiates the increases in extracellular monoamines induced by duloxetine in rat hypothalamus. J Neurochem 66:599-603

Gartside SE, Umbers V, Hajós M, Sharp T (1995): Interaction between a selective $5-\mathrm{HT}_{1 \mathrm{~A}}$ receptor antagonist and an SSRI in vivo: Effects on 5-HT cell firing and extracellular 5-HT. Br J Pharmacol 115:1064-1070

Gobert A, Rivet JM, Cistarelli L, Melon C, Millan MJ (1997): Alpha(2)-adrenergic receptor blockade markedly potentiates duloxetine- and fluoxetine-induced increases in noradrenaline, dopamine, and serotonin levels in the frontal cortex of freely moving rats. J Neurochem 69:2616-2619

Halliday G, Harding A, Paxinos G (1995): Serotonin and Tachykinin Systems. In Paxinos G (ed), The Rat Nervous System. Sydney, Academic Press, pp 929-974

Hervás I, Artigas F (1998): Effect of fluoxetine on extracellular 5-hydroxytryptamine in the rat brain. Role of 5-HT autoreceptors. Eur J Pharmacol 358:9-18

Invernizzi R, Belli S, Samanin R (1992): Citalopram's ability to increase the extracellular concentration of serotonin in the dorsal raphe prevents the drug's effect in frontal cortex. Brain Res 584:322-324

Invernizzi R, Bramante M, Samanin R (1994): Chronic treatment with citalopram facilitates the effect of a challenge dose on cortical serotonin output: Role of presynaptic 5- $\mathrm{HT}_{1 \mathrm{~A}}$ receptors. Eur J Pharmacol 260:243-246

Invernizzi R, Velasco C, Bramante M, Longo A, Samanin R (1997): Effect of 5- $\mathrm{HT}_{1 \mathrm{~A}}$ receptor antagonists on citalopram-induced increase in extracellular serotonin in the frontal cortex, striatum, and dorsal hippocampus. Neuropharmacology 36:467-473
Kawahara H, Yoshida M, Yokoo H, Nishi M, Tanaka M (1993): Psychological stress increases serotonin release in the rat amygdala and prefrontal cortex assessed by in vivo microdialysis. Neurosci Lett 162:81-84

Kihara T, Ikeda M (1995): Effects of duloxetine, a new serotonin and norepinephrine uptake inhibitor, on extracellular monoamine levels in rat frontal cortex. J Pharmacol Exp Ther 272:177-183

Malagié I, Trillat A-C, Jacquot C, Gardier AM (1995): Effects of acute fluoxetine on extracellular serotonin levels in the raphe: An in vivo microdialysis study. Eur J Pharmacol 286:213-217

Malagié I, Trillat A-C, Douvier E, Anmella MC, Dessalles MC, Jacquot C, Gardier AM (1996): Regional differences in the effect of the combined treatment of WAY-100635 and fluoxetine. An in vivo microdialysis study. Naunyn-Schmied Arch Pharmacol 354:785-790

Mongeau R, Weiss M, de Montigny C, Blier P (1998): Effect of acute, short- and long-term milnacipran administration on rat locus coeruleus noradrenergic and dorsal raphe serotonergic neurons. Neuropharmacology 37:905-918

Moret C, Charveron M, Finberg JPM, Couzinier JP, Briley M (1985): Biochemical profile of midalcipran (F 2207), 1-phenyl-1-diethyl-aminocarbonyl-2-aminomethyl-cyclopropane (Z) hydrochloride, a potential fourth generation antidepressant drug. Neuropharmacology 24:12111219

Moret C, Briley M (1996): Effects of acute and repeated administration of citalopram on extracellular levels of serotonin in rat brain. Eur J Pharmacol 295:189-197

Moret C, Briley M (1997): Effects of milnacipran and pindolol on extracellular noradrenaline and serotonin levels in guinea pig hypothalamus. J Neurochem 69:815-822

Paxinos G, Watson C (1986): The Rat Brain in Stereotaxic Coordinates. Sydney, Academic Press

Pei Q, Zetterström T, Fillenz M (1990): Tail pinch-induced changes in the turnover and release of dopamine and 5hydroxytryptamine in different brain regions of the rat. Neuroscience 35:133-138

Richelson E (1978): Tricyclic antidepressants block histamine $\mathrm{H}_{1}$ receptors of mouse neuroblastoma cells. Nature 274:176-177

Richelson E, Nelson A (1984): Antagonism by antidepressants of neurotransmitter receptors of normal human brain in vitro. J Pharmacol Exp Ther 230:94-102

Romero L, Hervás I, Artigas F (1996): The 5-HT ${ }_{1 \mathrm{~A}}$ antagonist WAY-100635 selectively potentiates the presynaptic effects of serotonergic antidepressants in rat brain. Neurosci Lett 219:123-126

Romero L, Artigas F (1997): Preferential potentiation of the effects of serotonin uptake inhibitors by $5-\mathrm{HT}_{1 \mathrm{~A}}$ receptor antagonists in the dorsal raphe pathway: Role of somatodendritic autoreceptors. J Neurochem 68:2593-2603

Romero L, Casanovas JM, Hervás I, Cortés R, Artigas F (1997): Strategies to optimize the antidepressant action of selective serotonin reuptake inhibitors. In Skolnick P (ed), Antidepressants: New Pharmacological Strategies. Totowa, NJ, Humana Press, pp 1-33

Rutter JJ, Gundlah C, Auerbach SB (1994): Increase in extra- 
cellular serotonin produced by uptake inhibitors is enhanced after chronic treatment with fluoxetine. Neurosci Lett 171:183-186

Sharp T, Bramwell SR, Grahame-Smith DG (1990): Release of endogenous 5-hydroxytryptamine in rat ventral hippocampus evoked by electrical stimulation of the dorsal raphe nucleus as detected by microdialysis: Sensitivity to tetrodotoxin, calcium, and calcium antagonists. Neuroscience 39:629-637

Shimizu N, Take S, Hori T, Oomura Y (1992): In vivo measurement of hypothalamic serotonin release by intracerebral microdialysis: Significant enhancement by immobilization stress in rats. Brain Res Bull 28:727-734

Singewald N, Kaehler S, Hemeida R, Philippu A (1997): Release of serotonin in the rat locus coeruleus: Effects of cardiovascular, stressful, and noxious stimuli. Eur J Neurosci 9:556-562

Starke K, Montel H (1973): Involvement of $\alpha$-receptors in clonidine-induced inhibition of transmitter release from central monoamine neurones. Neuropharmacology 12:1073-1080

Stenger A, Couzinier JP, Briley M (1987): Psychopharmacology of midalcipran, 1-phenyl-1-diethyl-amino-carbonyl-2-aminomethylcyclopropane hydrochloride (F 2207), a new potential antidepressant. Psychopharmacology 91:147-153

Svensson TH, Bunney BS, Aghajanian GK (1975): Inhibition of both noradrenergic and serotonergic neurons in brain by the $\alpha$-adrenergic agonist clonidine. Brain Res 92:291-306

Tao R, Hjorth S (1992): $\alpha_{2}$-adrenoceptor modulation of rat ventral hippocampal 5-hydroxytryptamine release in vivo. Naunyn-Schmied Arch Pharmacol 345:137-143

Yoshioka M, Matsumoto M, Togashi H, Saito H (1995): Effects of conditioned fear stress on 5-HT release in the rat prefrontal cortex. Pharmacol Biochem Behav 51:515-519 